\title{
Assessment of Oxidative Stress with Thiol Disulfide Homeostasis and Ischemia-Modified Albumin Level in Acute Urticaria
}

\author{
Ismail Erkan Aydin $^{1(\mathbb{D})}$, Seyda Tuba Savrun ${ }^{1(\mathbb{D})}$, Atakan Savrun ${ }^{1(\mathbb{D})}$, Sevda Onder ${ }^{2(\mathbb{D})}$, Salim Neselioglu ${ }^{3(\mathbb{D})}$, \\ Ozcan Erel $^{3(\mathrm{ID})}$, Yeliz Kasko Arici ${ }^{4(\mathrm{ID})}$ \\ ${ }^{1}$ Department of Emergency Medicine, Faculty of Medicine, Ordu University Ordu, Turkey \\ ${ }^{2}$ Department of Dermatology, Faculty of Medicine, Ordu University, Ordu, Turkey \\ ${ }^{3}$ Department of Medical Biochemistry, Faculty of Medicine Yıldırım Beyazıt University, Ankara, Turkey \\ ${ }^{4}$ Department of Bioistatistics and Medical Informatics Unit, Faculty of Medicine, Ordu, Turkey
}

Copyright@ Author(s) - Available online at https://dergipark.org.tr/en/pub/mbsjohs Content of this journal is licensed under a Creative Commons Attribution-NonCommercial 4.0 International License,

Received: 02 April 2020, Accepted: 15 April 2021, Published online: 30 April 2021 (C) Ordu University Institute of Health Sciences, Turkey, 2021

\begin{abstract}
Objective: There is no study in the literature investigating ischemia-modified albumin (IMA) values and thiol disulfide homeostasis (TDH) parameters in acute urticaria patients. This study aimed assessment of TDH parameters and IMA in acute urticaria patients.

Methods: The study included a total of 68 cases, with 35 acute urticaria patients and 33 healthy volunteers. Patients who presented to Ordu University Hospital and were diagnosed with acute urticaria between January 2019 and June 2019 and healthy individuals as the control group were included in the study. Serum albumin, IMA, native thiol, total thiol, and disulfide thiol levels were measured, and the results were compared between the groups.

Results: IMA values of $0.93 \pm 0.09$ in the study group were significantly high compared to $0.8 \pm 0.10$ in the control group $(\mathrm{p}<0.01)$. Native thiol $(\mathrm{SH})$ level was $353.66 \pm 87.5$ in the study group, $393.62 \pm 47.7$ in the control group (p:0.022), and total thiol (TSH) level was $385.46 \pm 86.6$ in the study group and $433.53 \pm 56.06$ in the control group (p:0.008). In the patient group there was a significant negative correlation between $\mathrm{SH}$ levels and IMA levels $(\mathrm{r}=-0.626, \mathrm{p}<0.001)$.

Conclusion: In acute urticaria, IMA increases while SH and TSH levels reduce. However, TDH does not change. The lack of change in the balance may be explained by acute urticaria being an acute event and not being a chronic inflammatory process.

Key words: acute urticaria, thiol disulfide, ischemia-modified albumin, oxidative stress

Suggested Citation Aydin IE, Savrun ST, Savrun A, Onder S, Neselioglu S, Erel O, Kasko Arici Y. Assessment of oxidative stress with thiol disulfide homeostasis and ischemia-modified albumin level in acute urticaria. Mid Blac Sea Journal of Health Sci, 2021; $7(1): 115-121$
\end{abstract}

\section{Address for correspondence/reprints:}

Ismail Erkan Aydin

Telephone number: +90 5056107590

E-mail: erkanaydinmd@gmail.com

$$
\text { Introduction }
$$

Urticaria is a disease occurring as itchy and edematous papules/plaques called urtica, with 
angioedema (AE) linked to deep dermis or subcutis involvement or development of one or the other. Clinical tableau lasting less than six weeks is called acute urticaria (AU), while clinical tableau lasting six weeks or longer is called chronic urticaria (CU). Nearly $15-20 \%$ of people are determined to experience one $\mathrm{AU}$ attack during a period of their lives (1).

The most common triggers of $\mathrm{AU}$ attacks are infections, medications, and foods; however, in 50\% of patients the situation remains idiopathic. Detailed history and physical examination are required for assessment of AU patients (2).

The balance between oxidants and antioxidants in the organism is the basis of preserving cellular and biochemical functions. Oxidants damage lipids, proteins and DNA in cells and even cause death $(3,4)$. The most common and rapidly affected proteins are thiols containing sulfhydryl. Plasma thiols are strong antioxidants physiologically removing free radicals (ROS). Serum levels of plasma thiols are counted among markers showing antioxidant levels in the body (5). Normally there is a balance between thiols and disulfides, and these play a protective role for cellular redox homeostasis. This is called dynamic thiol/disulfide homeostasis. Defects in this balance may be associated with a variety of diseases (6). There is increasing evidence that ROSs play a role in the pathogenesis of a variety of inflammatory and allergic diseases including urticaria $(7,8)$.

In recent times, another marker known as an oxidative stress marker is ischemia-modified albumin (IMA). Recent studies have shown ischemiamodified albumin (IMA) levels increase in free oxygen radicals formed because of ischemia, acidosis, or oxidative stress. The most common use is early myocardial injury. There are studies showing IMA levels increase in diseases causing oxidative stress like non-cardiac hypoxia, chronic renal disease, hypercholesterolemia, systemic sclerosis, and type 2 diabetes mellitus. In recent years, high levels of IMA are associated with a variety of diseases linked to oxidative stress (9).

There are very few studies about the correlation with oxidative stress in urticaria $(4,10)$. There are a variety of studies reporting contradictory information about the oxidative stress status of chronic idiopathic urticaria patients. However, the number of studies investigating the thiol disulfide homeostasis in urticaria is very low and the majority are associated with chronic urticaria $(4,10-12)$. There is no study in the literature investigating IMA values and TDH parameters in acute urticaria patients. In this sense, our study is the first to investigate IMA and TDH parameters together in acute urticaria patients. With this aim, the new oxidative stress markers of thiol disulfide homeostasis and ischemia-modified albumin and the place of oxidative stress in acute urticaria pathogenesis was investigated.

\section{Methods}

The study included a total of 68 cases, with 35 being acute urticaria patients and 33 healthy volunteers. Patients who presented to Ordu University Hospital and were diagnosed with acute urticaria between January 2019 and June 2019 and healthy individuals as the control group were included in the study. Patients with physical urticaria and urticarial vasculitis were excluded from the study.

Serum albumin, ischemia-modified albumin, native thiol, total thiol and disulfide thiol levels were measured, and the results were compared between the groups. Patients' demographic data such as age and gender, vital signs, symptoms, lesion onset time, and urticaria activity score according to Turkey's urticaria diagnosis and treatment guidelines 2016 were recorded.

\section{Biochemical analyses}

Venous blood samples of cases attending with acute urticaria attack symptoms were taken in smooth gel tubes for biochemical tests (Becton Dickinson and Company, New Jersey, USA) and plasma samples for TDH tests were taken in EDTA tubes (Becton Dickinson and Company, New Jersey, USA). All samples were centrifuged at $1600 \times \mathrm{xg}$ for 10 minutes and stored at $-70{ }^{\circ} \mathrm{C}$ until study. Biochemical tests were studied with an AU 2700 autoanalyzer (Beckman Coulter Inc. USA) with spectrophotometric methods.

Thiol measurements were assessed with spectrometry (Roche, cobas 501, Mannheim, Germany) using Erel et al.'s"modified Ellman method". Disulfide bonds (-S-S) were broken with sodium borohydride $(\mathrm{NaBH} 4)$ to create free functional thiol groups (-SH). Unused sodium borohydride waste was removed with formaldehyde. In this way, reduction of any disulfide bond created by the DTNB reaction with 5,5'-dithiobis-(2nitrobenzoic) acid (DTNB) was prevented. As a result of the DTNB reaction, total thiol groups were determined as reduced and native thiols. Disulfide parameter is a parameter calculated as half of the $\mathrm{SH}$ and TSH content. After $\mathrm{SH}$ and TSH were determined, SS, SS/SH+SS $\%, \mathrm{SH} / \mathrm{SH}+\mathrm{SS} \%$ and $\mathrm{SS} / \mathrm{SH} \%$ were calculated. 
Ischemia-modified albumin was analyzed with the albumin cobalt binding (CAB) test. The serum sample had $50 \mathrm{~mL} 0.1 \%$ cobalt (II) chloride added (CoCl2, 6H2O) (Sigma-Aldrich ChemieGmbHRiedstrasse 2, Steinheim, Germany). After waiting 10 minutes, binding of albumin to cobalt was ensured and $50 \mathrm{~mL} \quad 1.5 \mathrm{mg} / \mathrm{mL}$ dithiothreitol was added. After waiting for the 2minute incubation period, $1.0 \mathrm{~mL} 0.9 \%$ sodium chloride solution was added. Using a spectrophotometer at $470 \mathrm{~nm}$, the absorbance of samples was measured (Jenway $6315 \mathrm{UV} /$ visible Scanning Spectrophotometers, United Kingdom). Results are given as $\mathrm{mg} / \mathrm{dL}$. The albumin concentration was calculated by using the bromocresol green staining method (Biolabo, LesHautesRives, 02160, Maizy, France).

\section{Statistical analysis}

All data analyses were conducted using the SPSS v25 (IBM Inc., Chicago, IL, USA) statistical software package. Prior to the statistical analyses, the data were tested for normality using the Shapiro-Wilks test and for homogeneity of variance using the Levene's test. Independent samples t-test was used to assess differences between two groups. Crosstabulations were generated to describe the relationship between categorical variables, and the independence check was performed on the crosstabulations using a chi-square test $(\chi 2)$ and Contingency Coefficient (CC). Likelihood Ratio Chisquare values $(\mathrm{LR} \chi 2)$ were calculated for frequencies below 5. The Pearson's correlation analysis test was used to determine the relation between continuous variables. All comparisons were two-tailed and $\mathrm{P}$ value less than 5\% was considered statistically significant.

\section{Power analysis}

The sample size for this study was estimated by a priori power analysis using GPower 3.1 (Universität Düsseldorf, Düsseldorf) statistical software; assuming a large effect size $(\mathrm{d}=0.80), \alpha=0.05$ and 1 $\beta=0.80$, a minimum sample size of 26 in each group was required to detect the significance of the independent groups in the t-test.

\section{Ethics of the Study}

This study was approved by the local ethic committee of Ordu University Medical Faculty with the 2018/234 numbered decision. All participants were informed in detail about the objective of the study and gave written consent. The study was performed in accordance with the ethical principles of the Declaration of Helsinki.

\section{Results}

A total of 35 patients with urticaria (patient group) and 33 healthy subjects (control group) participated in this study. IMA values were significantly higher in the patient group than in the control group $(\mathrm{p}<0.01)$. Native thiol (SH), Total thiol values were significantly lower in the patient group than in the control group $(p<0.01)$. No other differences regarding study variables were observed between the patient group and the control group ( $p>0.05)$ (Table $1)$.

Table 1. Descriptive statistics and comparison results for the study variables in the patient and control groups.

\begin{tabular}{|c|c|c|c|}
\hline & Control $(n=33)$ & Patient $(n=35)$ & P-Value \\
\hline Albumin & $\begin{array}{c}4.476 \pm 1.551 \\
(1.5-7.2)\end{array}$ & $\begin{array}{c}4.559 \pm 1.432 \\
(1.7-7.6)\end{array}$ & $\begin{array}{c}0.819^{\mathrm{NS}} \\
(\mathrm{t}=-0.230)\end{array}$ \\
\hline IMA & $\begin{array}{c}0.848 \pm 0.106 \\
(0.6-1.1)\end{array}$ & $\begin{array}{c}0.936 \pm 0.096 \\
(0.7-1.09)\end{array}$ & $\begin{array}{c}0.001 * * \\
(\mathrm{t}=-3.582)\end{array}$ \\
\hline NATIVE THIOL (SH) & $\begin{array}{c}393.621 \pm 47.727 \\
(239.8-481.0)\end{array}$ & $\begin{array}{c}353.669 \pm 87.506 \\
(145.5-517.9)\end{array}$ & $\begin{array}{c}0.022^{*} \\
(\mathrm{t}=2.355)\end{array}$ \\
\hline TOTAL THIOL & $\begin{array}{c}433.536 \pm 56.067 \\
(267.8-549.0)\end{array}$ & $\begin{array}{c}385.469 \pm 86.663 \\
(187.5-549.0)\end{array}$ & $\begin{array}{l}0.008 * * \\
(\mathrm{t}=2.731)\end{array}$ \\
\hline DISULFIDE (SS) & $\begin{array}{c}19.958 \pm 7.772 \\
(1.0-36.0)\end{array}$ & $\begin{array}{c}16.95 \pm 3.64 \\
(8.0-23.0)\end{array}$ & $\begin{array}{l}0.051^{\mathrm{NS}} \\
(\mathrm{t}=1.99)\end{array}$ \\
\hline SS/SH \% & $\begin{array}{c}5.052 \pm 1.718 \\
(0.2-7.8)\end{array}$ & $\begin{array}{c}4.916 \pm 2.519 \\
(0.9-14.4)\end{array}$ & $\begin{array}{c}0.797^{N S} \\
(t=0.259)\end{array}$ \\
\hline SS/TOTAL THIOL \% & $\begin{array}{c}4.544 \pm 1.449 \\
(0.2-6.8)\end{array}$ & $\begin{array}{c}4.387 \pm 1.980 \\
(0.8-11.2)\end{array}$ & $\begin{array}{l}0.711^{\mathrm{NS}} \\
(\mathrm{t}=0.371)\end{array}$ \\
\hline SH / TOTAL THIOL \% & $\begin{array}{c}90.910 \pm 2.896 \\
(86.5-99.6) \\
\end{array}$ & $\begin{array}{c}91.225 \pm 3.961 \\
(77.6-98.3) \\
\end{array}$ & $\begin{array}{c}0.711^{\mathrm{NS}} \\
(\mathrm{t}=-0.372)\end{array}$ \\
\hline
\end{tabular}

Mean \pm Standard Deviation (Minimum-Maximum); t, Independent samples t-test.

NS Statistically not significant $(\mathrm{p}>.05) ; *$ Statistically significant $(\mathrm{p}<0.05) ; * *$ Statistically significant $(\mathrm{p}<0.01)$. 
In the patient group, there was a significant negative correlation between the native thiol $(\mathrm{SH})$ levels and the IMA levels $(r=-0.626, p<0.001)$. In the patient group, there was a significant positive correlation between the $\mathrm{SS} / \mathrm{SH}(\%)$ levels and the IMA levels (r=-
$0.626, \mathrm{p}<0.001)$. Native thiol decreased significantly as IMA increased in the patient group $(\mathrm{r}=-0.684$, $\mathrm{p}<0.001 ; \mathrm{r}=-0.626, \mathrm{p}<0.001$, respectively) (Table 2 and Table 3).

Table 2. Pearson correlation coefficients between the study variables of patient and control groups.

\begin{tabular}{|c|c|c|c|c|c|c|c|c|c|}
\hline & & $\begin{array}{c}\text { ALBUM } \\
\text { IN }\end{array}$ & IMA & $\begin{array}{c}\text { NATIVE } \\
\text { THIOL } \\
\text { (SH) }\end{array}$ & $\begin{array}{l}\text { TOTAL } \\
\text { THIOL }\end{array}$ & $\begin{array}{c}\text { DISUL } \\
\text { FIDE } \\
(\mathrm{SS})\end{array}$ & $\begin{array}{c}\text { SS/SH } \\
\%\end{array}$ & $\begin{array}{c}\text { SS/TOT } \\
\text { AL } \\
\text { THIOL } \\
\%\end{array}$ & $\begin{array}{c}\text { SH/TOT } \\
\text { AL } \\
\text { THIOL } \\
\%\end{array}$ \\
\hline \multirow[t]{2}{*}{ Albumın } & $\mathrm{r}$ & & -0.232 & 0.043 & 0.044 & 0.009 & -0.046 & -0.032 & 0.032 \\
\hline & $\mathrm{P}$ & & 0.181 & 0.808 & 0.801 & 0.960 & 0.793 & 0.857 & 0.855 \\
\hline \multirow[t]{2}{*}{ Ima } & $r$ & -0.088 & & -0.626 & -0.620 & 0.102 & 0.410 & 0.409 & -0.410 \\
\hline & $\mathrm{P}$ & 0.627 & & $0.000 * * *$ & $0.000 * * *$ & 0.560 & $0.014 *$ & $0.015^{*}$ & $0.014 *$ \\
\hline Natıve & $\mathrm{r}$ & 0.327 & -0.684 & & 0.994 & -0.141 & -0.693 & -0.686 & 0.687 \\
\hline Thıol (Sh) & $\mathrm{P}$ & 0.063 & $0.000 * * *$ & & $0.000 * * *$ & 0.418 & $\begin{array}{c}0.000 * * \\
*\end{array}$ & $0.000 * * *$ & $0.000 * * *$ \\
\hline Total & $\mathrm{r}$ & 0.303 & -0.665 & 0.968 & & -0.029 & -0.618 & -0.607 & 0.607 \\
\hline Thiol & $\mathrm{P}$ & 0.087 & $0.000 * * *$ & $0.000 * * *$ & & 0.871 & $\begin{array}{c}0.000^{* *} \\
*\end{array}$ & $0.000 * * *$ & $0.000 * * *$ \\
\hline Disulfide & $\mathrm{r}$ & 0.088 & -0.298 & 0.421 & 0.635 & & 0.716 & 0.755 & -0.755 \\
\hline (Ss) & $\mathrm{P}$ & 0.627 & 0.092 & $0.015^{*}$ & $0.000 * * *$ & & $\begin{array}{c}0.000 * * \\
*\end{array}$ & $0.000 * * *$ & $0.000 * * *$ \\
\hline Ss/Sh \% & $\mathrm{r}$ & -0.022 & -0.088 & 0.091 & 0.337 & 0.937 & & 0.996 & -0.996 \\
\hline & $\mathrm{P}$ & 0.905 & 0.627 & 0.616 & 0.055 & $\begin{array}{c}0.000 * * \\
*\end{array}$ & & $0.000 * * *$ & $0.000 * * *$ \\
\hline Ss/Total & $\mathrm{r}$ & -0.010 & -0.072 & 0.077 & 0.324 & 0.933 & 0.999 & & \\
\hline Thiol \% & $\mathrm{P}$ & 0.954 & 0.692 & 0.671 & 0.066 & $\begin{array}{c}0.000 * * \\
*\end{array}$ & $\begin{array}{c}0.000 * * \\
*\end{array}$ & & \\
\hline Sh/Total & $r$ & 0.010 & 0.072 & -0.077 & -0.324 & -0.933 & -0.999 & -1.000 & \\
\hline Thıol & $\mathrm{P}$ & 0.956 & 0.690 & 0.670 & 0.066 & $\begin{array}{c}0.000 * * \\
*\end{array}$ & $\begin{array}{c}0.000 * * \\
*\end{array}$ & $0.000 * * *$ & \\
\hline
\end{tabular}

$r$, Pearson correlation coefficient in the patient group; $r$, Pearson correlation coefficient in the control group.

*, Statistically significant $(\mathrm{p}<0.05)$; ***, Statistically significant $(\mathrm{p}<0.001)$.

Table 3. Pearson correlation coefficients between the study variables of patient and control groups.

\begin{tabular}{|c|c|c|c|c|c|c|}
\hline & \multicolumn{3}{|c|}{ Control $(n=33)$} & \multicolumn{3}{|c|}{ Patient $(n=35)$} \\
\hline & IMA & NAT. $T$ & TOTAL T & IMA & NAT. $T$ & TOTAL T \\
\hline $\begin{array}{l}\text { NATIVE } \\
\text { THIOL (SH) }\end{array}$ & $\begin{array}{c}- \\
0.684 * * *\end{array}$ & & & $-0.626 * * *$ & & \\
\hline $\begin{array}{l}\text { TOTAL } \\
\text { THIOL }\end{array}$ & $\begin{array}{c}- \\
0.665^{* * *}\end{array}$ & $0.968 * * *$ & & $-0.620 * * *$ & $0.994 * * *$ & \\
\hline $\begin{array}{l}\text { DISULFIDE } \\
\text { (SS) }\end{array}$ & -0.298 & $0.421 *$ & $0.635 * * *$ & 0.088 & -0.192 & -0.113 \\
\hline Index I & -0.088 & 0.091 & 0.337 & $0.410 *$ & $-0.693 * * *$ & $-0.618 * * *$ \\
\hline Index 2 & -0.072 & 0.077 & 0.324 & $0.409 *$ & $-0.686 * * *$ & $-0.607 * * *$ \\
\hline Index 3 & 0.072 & -0.077 & -0.324 & $-0.410 *$ & $0.687 * * *$ & $0.607 * * *$ \\
\hline
\end{tabular}

$\mathrm{r}$, Pearson correlation coefficient

$*, \mathrm{p}<0.05 ; * * *, \mathrm{p}<0.001$

\section{Discussion}

There is a balance between free radical production and the antioxidant system suppressing the increase in ROS in the body. If this balance is disrupted, oxidative stress (OS) occurs. There are studies assessing the oxidative stress in urticaria patients. Some studies have shown an increase in OS, while some studies have chosen no change in OS (13-17).
Most studies researching oxidative stress have been performed on chronic urticaria patients $(4,10-12)$.

Oxidative stress has been studied in acute urticaria (AU) and chronic urticaria patient groups with different markers such as malondialdehyde (MDA), glutathione peroxidase (GSH-Px) and catalase (CAT). Studies by Kalkan et al. compared acute urticaria patients with healthy controls and found $\mathrm{Cu} / \mathrm{ZN}$ superoxide dismutase (SOD) activities and 
MDA levels were high and plasma GSH-PX activity reduced $(1,10,14)$. In allergic diseases, especially asthma and to a lesser degree atopic dermatitis, there is increasing literature about the role of oxidative stress.

Free radicals occurring due to normal metabolism or pathologic processes disrupt the structure and functions of thiol dependent enzymes and cause changes in the thiol/disulfide ratio in the cell environment. Reduced plasma thiol concentration shows increased production of free radicals (6). In this study native thiol and total thiol levels reduced but disulfide thiol levels did not increase. But another oxidant parameter, IMA increased. Reduced native thiol levels are not definitely associated with increasing disulfide levels and similarly increased native thiol levels are not definitely associated with reduced disulfide levels. This may be associated with the immune response of thiols to inflammation. Reduced plasma thiol concentration is proof of free radical production. Reduced thiol levels are also associated with leukocyte activation. Urticaria mast cells are associated with immunologic activation and inflammation with oxidative stress (OS) activation of basophils and eosinophils and finally increased ROS (18). Stimulation of all inflammatory cells produces a significant amount of ROS. Eosinophils have higher peroxidase levels compared to other inflammatory cells and have a unique role in formation of oxidative stress (19).

In the acute urticaria patient group in our study, we identified reduced SH and TSH levels compared to the healthy control group. In the literature there are studies of dynamic thiol/disulfide homeostasis in different diseases. Eren et al. (20) showed total thiols were clearly reduced in migraine patients compared to a control group. Ates et al. (21) showed primary hypertension patients had total disulfide balance moving toward disulfide. Kundi et al. (22) identified reduced native and total thiol levels in patients with acute myocardial infarction compared to the control group and stated that thiol/disulfide homeostasis may be a new oxidative stress (OS) marker for acute myocardial infarction patients. A study by Ozyazıcı et al. (23) stated that the total disulfide balance had slid toward disulfide linked to thiol oxidation in a patient group with acute appendicitis and that this balance may be an OS marker for acute appendicitis patients. Yilmaz et al. (24) reported research on the thiol/disulfide homeostasis in asphalt workers exposed to polycyclic aromatic hydrocarbons.

In ischemic conditions, the shape of the amino terminal tip (N-terminal) of albumin changes and metal binding capacity reduces. As a result, this new form is a new ischemia marker called ischemiamodified albumin (IMA). Though IMA levels were initially considered specific to ischemia, superoxide radical damage, and exposure to free iron and copper have been shown to cause IMA formation (25). Based on these factors, in addition to ischemia-associated diseases, IMA values were shown to increase in some inflammatory diseases (26-28). In our study, a significant increase was identified in IMA levels in the acute urticaria patients compared to the control group.

Ozdemir et al. (29) reported increased IMA levels in patients with psoriasis due to an adaptive response to oxidative stress and systemic inflammation. However, Erem et al. (30) found the IMA irrelevant to oxidative stress.

Mast cells are known to play an important role in allergic diseases. As a result of antigen exposure, mast cells are sensitized and release many mediators causing allergic symptoms (31). Oxidative stress may ease degranulation of mast cells in response to allergens contributing to the development of allergic reactions. In the literature, there are some studies showing an association between oxidative stress and a variety of allergic diseases $(3,13,14,19,31,32)$. Patella et al. (32) found that hymenoptera venom allergy levels of advanced oxidation protein products were consistently high during immunotherapy. They suggested that an oxidative stress state occurs in patients with hymenoptera allergy.

The colorimetric test performed on serum is based on decreased binding of exogenous cobalt to albumin which occurs in tissue damage caused by free radicals. (33). This issue was supported by the reports suggesting that IMA is strongly related with oxidative stress rather than being a myocardial ischemia marker $(34,35)$.

\section{Limitations}

The lack of follow-up data, single blood sampling and small sample size are the limitations of our study. This study does not allow any conclusion about the causative correlation between acute urticaria and underlying interactions. To clarify the underlying mechanisms, it is necessary to confirm these findings in future studies with larger sample sizes.

\section{Conclusions}

Acute urticaria is a disease without definitely known cause. There are studies related to OS as a part of studies about etiopathogenesis. In our study, our objective data identified that $\mathrm{SH}$ and TSH levels reduce, and IMA values increase in AU. In 
conclusion, based on our data and literature information, we think increased IMA levels and reduced $\mathrm{SH}$ and TSH levels may be markers of oxidative stress in acute urticaria.

Ethics Committee Approval: Clinical Studies Ethics Committee of Ordu University, Faculty of Medicine, Decision number: 2018-234 Date: 15 November 2018

Peer-review: Externally peer-reviewed.

\section{Author Contributions:}

Concept: A.S. Design: A.S., S.O. Literature Search: A.S., S.O. Data Collection and Processing: I.E.A, S.N, O.E, Y.K.A. Analysis and/or Interpretation: I.E.A, S.T.S, S.O. Y.K.A. Writing: I.E.A, S.T.S.

Conflict of Interest: No conflict of interest was declared by the authors.

Financial Disclosure: The authors declared that this study hasn't received no financial support.

\section{References}

1. Goncu Kocaturk E, Aktan Ş, Atakan N, Başkan EB, Erdem T, Koca R, et al. The Turkish Guideline for the Diagnosis and Management of Urticaria-2016. Turkderm-ArchTurk Dermatol Venerology. 2016;50:82-98.

2. Kulthanan K, Chiawsirikajorn Y, Jiamton S. Acute urticaria: etiologies, clinical course and quality of life. Asian Pac J Allergy Immunol. 2008;26:1-9.

3. Akbas A, Kilinc F, Sener S, Aktaş A, Baran P, Ergin $\mathrm{M}$, et al. Investigation of thiol-disulphide balance in patients with acute urticaria and chronic spontaneous urticaria. Cutan Ocul Toxicol. 2017;36(3):205-210.

4. Briganti S, Picardo M. Antioxidant activity, lipid peroxidation and skin diseases. What's new? J Eur Acad Dermatol Venereol. 2003;17:663-669.

5. Bickers DR, Athar M. Oxidative stress in the pathogenesis of skin disease. J Invest Dermatol. 2006;126:2565-2575.

6. Korkmaz V, Kurdoglu Z, Alisik M, Cetin O, Korkmaz H, Surer H, et al. Impairment of thioldisulfidehomeostasis in preeclampsia. J Matern Fetal Neonatal Med. 2016;29(23):3848-53.

7. Okayama Y. Oxidative stress in allergic and inflammatory skin diseases. Curr Drug Targets Inflamm Allergy. 2005;4:517-519.

8. Cassano N, De Meo M, Scoppio BM, Loviglio MC, Del Vecchio S, Vena G. A.Does oxidative stress play a role in the pathogenesis of urticarias? Eur J Inflamm. 2005;3:5-10.

9. Cichota LC, Moresco RN, Duarte MMMF, Silva
JEPD. Evaluation of ischemia-modified albumin in anemia associated to chronic kidney disease. $\mathbf{J}$ Clin Lab Anal. 2008;22:1-5.

10. Raho G, Cassano N, D'Argento V, Vena GA, Zanotti F. Overexpression of $\mathrm{Mn}$-superoxide dismutase as a marker of oxidative stress in lesional skin of chronic idiopathic urticaria. Clin Exp Dermatol. 2003;28:318-320.

11.Cassano N, Raho G, Filieri M, D'Argento V, Amoruso A, Filotico R, et al. Influence of desloratadine on oxidative stress markers in patients with chronic idiopathic urticaria. Int $\mathbf{J}$ Dermatol. 2006;45:394-396.

12.Kasperska-Zajac A, Brzoza Z, Rogala B, Polaniak R, Birkner E. Antioxidant enzyme activity and malondialdehyde concentration in the plasma and erythrocytes of patients with urticaria induced by nonsteroidal anti-inflammatory drugs. J Investig Allergol Clin Immunol. 2008;18:372-375.

13. Sagdic A, Sener O, Bulucu F, Karadurmus N, Yamanel L, Tasci C, et al. Oxidative stress status in patients with chronic idiopathic urticaria. Allergol Immunopathol (Madr). 2011;39:150153.

14.Kalkan G, Seckin HY, Duygu F, Akbaş A, Özyurt $\mathrm{H}$, Şahin M. Oxidative stress status in patients with acute urticaria. Cutan Ocul Toxicol. 2014;33:109-114.

15.Briganti S, Cristaudo A, D'argento V, Cassano N, Turbino L, Guarrera M, et al. Oxidative stress in physical urticarias. Clin Exp Dermatol. 2001;26:284-288.

16.Kasperska-Zajac A, Brzoza Z, Rogala B, Polaniak $\mathrm{R}$, Birkner E. Antioxidant enzyme activity and malondialdehyde concentration in the plasma and erythrocytes of patients with urticaria induced by nonsteroidal anti-inflammatory drugs. J Investig Allergol Clin Immunol. 2008;18:372-375.

17. Mushtaq A, Khan MN, Khursheed R, Qureshi MS, Malik A, Zahid S, et al. Antioxidant enzyme activity and malondialdehyde concentration in patients with urticaria induced by non steroidal anti-inflammatory drugs. Ann Punjab Med Coll. 2012;6(2):110-114.

18. Knight JA. Review: free radicals, antioxidants, and the immune system. Ann Clin Lab. 2000;30:145-158.

19.Dilek F, Ozceker D, Ozkaya E, Guler N, Tamay $\mathrm{Z}$, Kesgin S, et al. Oxidative Stress in Children with Chronic Spontaneous Urticaria. Oxid Med Cell Longev. 2016;2016:3831071. 
20.Eren Y, Dirik E, Neselioglu S, Erel O. Oxidative stres and decreased thiol levels in patients with migraine: crosssectional study. Acta Neurol Belg. 2015;115:643-649.

21.Ates I, Ozkayar N, Inan B, Yilmaz FM, Topcuoglu C, Neselioglu S, et al. Dynamic thiol/disulphide homeostasis in patients with newly diagnosed primary hypertension. J Am Soc Hypertens. 2016;10(2):159-66.

22.Kundi H, Ates I, Kiziltunc E, Cetin, M, Cicekcioglu H, Neselioglu S, et al. A Novel oxidative stres marker in acute myocardial infarction; thiol/disulphide homeostasis. Am J Emerg Med. 2015;33:1567-1571.

23. Ozyazici S, Karateke F, Turan U, Kuvvetli A, Kilavuz H, Karakaya B, et al. A Novel Oxidative Stress Mediator in Acute Appendicitis: Thiol/Disulphide Homeostasis. Mediators Inflamm. 2016;2016:6761050.

24. Yilmaz OH, Bal C, Neselioglu S, Buyuksekerci M, Gunduzoz M, Eren F, et al. Thiol/disulphide homeostasis in asphalt workers. Arch Environ Occup Health. 2016;71:268-272.

25.Sbarouni E, Georgiadou P, Voudris V. Ischemia modified albumin changes - review and clinical implications. Clin Chem Lab Med. 2011;49(2):177-84.

26.Toker A, Karatas Z, Altın H, Karaarslan S, Cicekler H, Alp H. Evaluation of serum ischemia modified albumin levels in acute rheumatic fever before and after therapy. Indian $\mathrm{J}$ Pediatr. 2014;81(2):120-5.

27.Can U, Yerlikaya FH, Yosunkaya S. Role of oxidative stress and serum lipid levels in stable chronic obstructive pulmonary disease. J Chin Med Assoc. 2015;78(12):702-8.

28. Kaplan M, Yuksel M, Ates I, Kilic ZMY, Kilic H, Kuzu U, et al. Is ischemia modified albumin a disease activity marker for inflammatory bowel diseases? J Gastroenterol Hepatol. 2016;31(6):1120-5.

29. Ozdemir M, Kivici A, Balevi A, Mevlitoğlu I, Peru C. Assessment of ischaemia- modified albumin level in patients with psoriasis. Clin Exp Dermatol. 2012;37:610-4.

30.Erem C, Suleyman AK, Civan N, Mentese A, Nuhoglu I, Uzun A, et al. Ischemia-modified albümin and malondialdehyde levels in patients with overt and subclinical hyperthyroidism: effects of treatment on oxidative stress. Endocr J. 2015;62:493-501.
31.Dadaci Z, Oncel M, Oncel Acir N, Sahin E, Borazan M. Oxidative stres parameters and serum magnesium levels in patients with seasonal allergic conjunctivitis. Cutan Ocul Toxicol. 2016;35(4):270-4.

32.Patella V, Incorvaia C, Minciullo PL, Oricchio C, Saitta S, Florio G, et al. Oxidative stress markers in patients with hymenoptera venom allergy. Allergy Asthma Proc. 2015;36:9-13.

33. Roy D, Quiles J, Gaze DC, Collinson P, Kaski JC, Baxter GF. Role of reactive oxygen species on the formation of the novel diagnostic marker ischaemia modified albumin. Heart $\mathrm{Br}$ Card Soc. 2006;92:113-114.

34.Borderie D, Allanore Y, Meune C, Devaux JY, Ekindjian OG, Kahan A. High ischemia-modified albumin concentration reflects oxidative stress but not myocardial involvement in systemic sclerosis. Clin Chem. 2004:50:2190-2193.

35.Kaefer M, Piva SJ, De Carvalho JA, Da Silva DB, Becker AM, Coelho AC, et al. Association between ischemia modified albumin, inflammation and hyperglycemia in type 2 diabetes mellitus. Clin Biochem. 2010;43:450454 